\title{
Fotografias feitas por pessoas deficientes visuais, por que não?
}

\section{Photography made by visually impaired people, why not?}

\section{João Kulcsár}

Centro Universitário Senac

\section{Resumo}

Ao dispararem o botão da câmera, focando a acessibilidade, pessoas com deficiência visual propõem uma discussão sobre a questão da técnica e da estética fotográfica, além de transformar o ato de fotografar num ato político, que nos faz repensar o conceito de cegueira.

Palavras-chave: Fotografia; Deficientes visuais; Alfabetização visual; Sentidos.

\section{Abstract}

When taking pictures, focusing on accessibility, people with visual impairment propose a discussion about the issue of technique and photographic aesthetics, as well as transform the act of photographing into a political act that makes us rethink the concept of blindness.

Keywords: Photography; Visually impaired;

Visual literacy; Senses. 


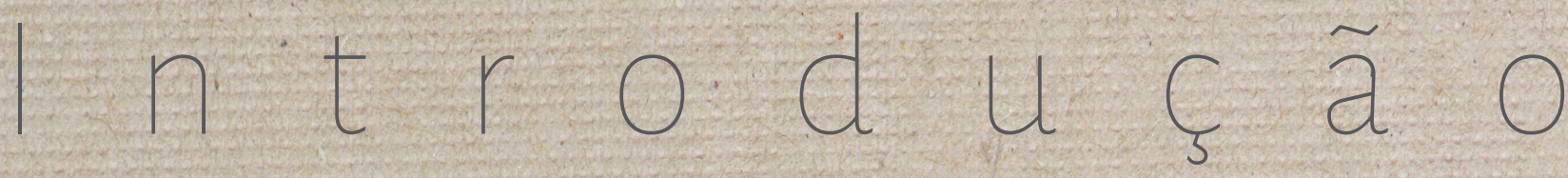

"Todos os fotógrafós precisam de um quarto escuro, devem revelar seus filmes em uma sala escura e toda a minha vida é uma sala escura, eu sou uma sala escura, usando uma máquina por onde entra a luz. Por que não poderia fazer fotos? Isso não é uma provocação, e sim um desejo interior de fazer imagens".

Evgen Bavcar (1994, p. 462), fotógrafo cego esloveno.

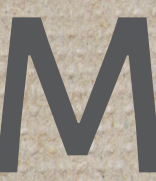
otivados por esse mesmo desejo interior de fazer imagens, de registrar os aspectos mais marcantes da vida como todos nósfazemos, os usuários do Espaço Braille da Biblioteca do Centro Universitário Senac solicitaram, em setembro de 2007, um curso de fotografia para deficientes visuais para o Projeto de Alfabetização Visual ${ }^{1}$. O fruto desta solicitação foi desenvolvido, e a partir de abril de 2008 iniciou-se o projeto de fotografia participativa com jovens e adultos deficientes visuais, no qual os alunos aprendem a usar a fotografia como meio de expressão criativa e inclusão social, comunicando suas percepções sobre o mundo e despertando consciência no público vidente sobre a realidade da comunidade cega.
Imagem 1 - Um sonho em movimento (1997), de Evgen Bavcar.

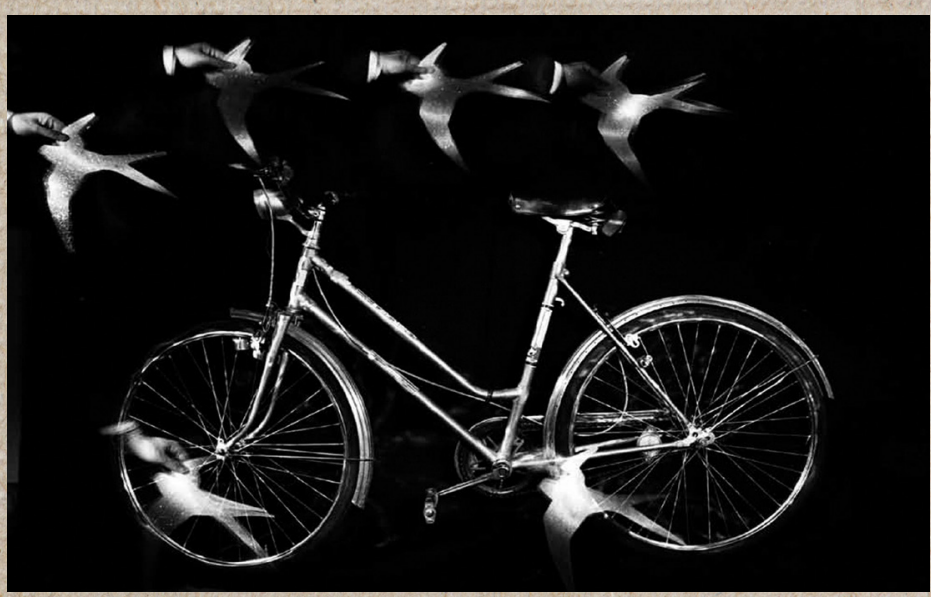

Fonte: Acervo pessoal de Evgen Bavcar (1997)

Descrição da imagem. Fotografia na horizontal, em preto e branco, mostrando uma bicicleta e seis pássaros em volta dela. Foi feita com a técnica light painting, iluminando mais algumas áreas do que outras.

10 conceito de alfabetização visual foi desenvolvido pelo professor João Kulcsár (1997) em sua pesquisa de mestrado, na Universidade de Kent (Inglaterra), entre 1996 e 1997, e na Universidade de Harvard (Estados Unidos), onde esteve como professor visitante em 2002 e 2003. O curso com deficientes visuais fez parte do projeto Alfabetização Visual, coordenado pelo professor João Kulcsár, e tem por objetivo capacitar alunos do curso de Bacharelado em Fotografia, Audiovisual, Design e Arquitetura do Senac para dar aulas de fotografia e alfabetização visual em projetos sociais de maneira refletiva, consciente e crítica. Atuando como educadores na prática de um determinado projeto, os alunos voluntários aprendem a preparar, conduzir e avaliar uma aula, ampliando, ao mesmo tempo, suas visões sobre as possibilidades da fotografia ao conhecer novas realidades e novos ol hares. 


\section{Preparação}

As aulas de fotografia para deficientes visuais, planejadas e ministradas por João Kulcsár e edu-' cadores (alunos dos cursos de bacharelado), acontecem semanalmente, no Centro Universitário Senac, em Santo Amaro, na zona sul de São Paulo, ou em outros espaços, de acordo com a necessidade. Antes do curso ser iniciado, foi necessário fazer a capacitação dos educadores no campo do relacionamento com este novo público. Todos os que participaram do projeto experimentaram vivências em alguns destes locais: Museu do Diálogo, em Campinas; Pinacoteca do Estado de São Paulo ; Associação Brasileira de Assistência à Pessoa com Deficiência Visual (Laramara); Fundação Dorina Nowill Para Cegos; e no próprio Espaço Braille da Biblioteca do Senac. O objetivo foi proporcionar oportunidade para aprender sobre os numerosos aspetos relacionados à experiência de trabalhar com deficientes visuais, desde a mobilidade até a leitura da imagem.

\section{Imagem 2 - Alfabetização Visual, de João Kulcsár (2015).}

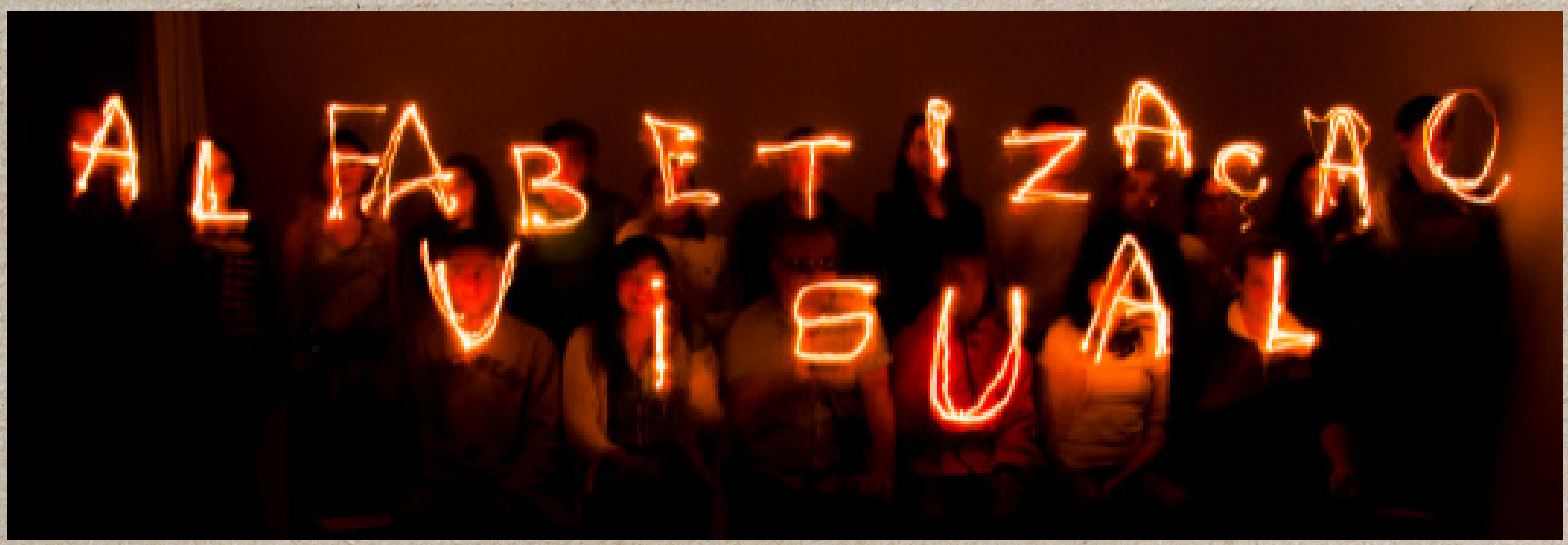

Fonte: Acervo Pessoal.

Descrição da imagem. Fotografia colorida na horizontal, na qual aparecem as palavras alfabetização visual, escritas com light painting. Cada letra foi produzida por uma pessoa durante uma aula no projeto. A cor das letras é laranja e as pessoas quase não aparecem, pois está escuro.

\section{Módulos}

As aulas no projeto são divididas em três módulos: Manuseio - no qual se aprende a segurare operar a câmera/celular; Sentidos - aproximação e desenvolvimento da expressão pelos outros 
sentidos; e Ensaio Fotográfico - no qual o participante escolhe um assunto para sua narrativa visual. No primeiro módulo são desenvolvidas as técnicas de distanciamento, enquadramento e composição, que envolvem uma interação espacial e corporal, tanto com o sujeito da foto como com a máquina fotográfica. São enfocadas também questões de autonomia, comunicação verbal e elaboração de perguntas para atingir a realização fotográfica.

O projeto tem como objetivo estimular a reflexão, a imaginação e a participação dos alunos, desenvolvendo sempre a autoestima e abrindo novos canais de comunicação e expressão entre a comunidade de deficientes visuais e o público vidente. Outra parte fundamental consiste na documentação, por escrito, por vídeo e por fotografia, das aulas e atividades do curso, que tem como fim a produção de um guia - hospedado no site oficial do projeto (www. alfabetizacaovisual.com.br, 2017), que pode servir como referência para outros educadores e artistas interessados em realizar projetos de fotografia participativa com deficientes visuais. Neste ano foi inclusive desenvolvido pelo projeto o primeiro curso gratuito de Ensino a Distância de fotografia para pessoas deficientes visuais.

Finalmente, no coração do projeto, as atividades são situadas no contexto de um processo maior, de trabalhar e lutar por um mundo que promove, nas palavras de Bavcar (1994, p.464), "a aceitação de todos que olham de outro modo".

Segundo um dos autores do projeto, Clodoaldo Barreira (2010, p. 7), "O homem superou limites e coisas que jamais pensava poderem ser superadas. Quando você fotografa e não tem que pedir para outra pessoa fotografar para você, acaba criando autonomia". O comentário sublinha não só, o grande potencial do curso em desenvolver confiança, autoestima e independência no dia-a-dia dos envolvidos, mas também destaca a importância de romper com os estereótipos impostos pela sociedade e desmistificar a condição de impotência à qual muitos deficientes visuais são submetidos. A etapa inicial evidenciou que este projeto, acima de tudo, envolve o tripé estético, técnico e ético, com uma metodologia participativa, conquistada de forma colaborativa, com auxílio de muitas mãos.

\section{A pergunta é "Por que fotografar?", e não “Como fotografar?"!}

A gente só escuta pessoas que não acreditam em nós, que perguntam: "Cego tirando foto? Que é isso?" (SILVEIRA, 2010). 
A pergunta, que chega sem falta a todos os alunos e educadores do projeto, pode vir em várias formas, mas sempre é a mesma: Como é que alguém que não enxerga consegue fazer uma foto?

Não existe uma única resposta a essa pergunta, senão múltiplas alternativas que foram e continuam se construindo. Uma destas respostas, talvez a mais contundente, são as próprias fotos dos alunos, provas imagéticas e tangíveis do fato de conseguir realizar o ato de fotografar. Afinal, o processo fotográfico não diverge, o mecanismo é o mesmo - selecionar uma cena, posicionar a câmera e acionar o botão. A motivação que desencadeia este processo é o mais importante. Cada fotógrafo tem sua própria intenção. Os resultados, as imagens, evidenciam os interesses de cada um.

No filme documentário Janela da Alma (2002), Evgen Bavcar afirma que "não devemos falar a língua dos outros e nem utilizar o olhar dos outros, porque nesse caso existimos através do outro. É preciso existir por si mesmo".

Fez-se necessária então uma compilação de diversos depoimentos que sublinham o desejo e a motivação dos participantes que fizeram parte do projeto. A partir dessa ideia, os participantes buscaram responder: "por que fotografar?".

"Com a fotografia, eu ajudo a quebrar vários paradigmas que a nossa sociedade acaba impondo". (OTON, 2010).

"A gente quer fotografar para deixar as coisas que a gente faz registradas, os passeios, por exemplo. Não é porque não enxergamos, mas porque foi gostoso. A gente quer mostrar para as outras pessoas que estivemos lá, que vivenciamos aquilo e então recordar. Eu sei que foi gostoso, pelo cheiro do mato, pelo canto dos passarinhos..." (MAIA, 2010).

"Adoro desafio. Como a fotografia é uma coisa nova para mim, estou com bastante curiosidade. Vou sair daqui descobrindo muita coisa. Adoro tudo que é desafio, é uma coisa maravilhosa". (SILVA, 2010).

"Eu também gosto bastante de desafios. Perdi a visão com cinco anos, já estou acostumado. Quero tirar muitas fotos". (AOKI, 2010).

"Tirei foto deles para não esquecer, disse o adolescente Henrique, depois de tirar foto dos bonecos do desenho Cavaleiros do.Zodíaco". (AOKI, 2010). 
"A fotografia é uma janela para o mundo". (OTON, 2010).

"É necessário fazermos fotos boas pela qualidade, não porque somos deficientes visuais". (MAIA, 2009).

"Eu achei que não fosse capaz de fotografar. Senti uma grande emoção quando falaram que minha primeira foto estava muito boa". (MORAES, 2010).

"Quando fotografo, penso que estou congelando o tempo. Procuro captar alguma coisa boa, uma expressão, uma imagem..." (MAIA,2010).

"As melhores coisas da vida nós fazemos de olhos fechados". (DOMINCUES, 2010).

"Não são todos os deficientes que se dispõem a superar desafios". (ARAUJO, 2010).

"No início eu sentia medo, pensei que não conseguiria. Já que consegui alcançar minha meta, agora é uma coisa muito prazerosa. Eu tiro fotos primeiro para mostrar para mim mesmo que eu posso, segundo para fazer um trabalho legal, espontâneo, e também para mostrar para os outros que eu posso". (SILVA, 2010).

\section{A fotografia e a deficiência visual}

Eu não acho que ficamos cegos. Acho que somos cegos. Cegos que podem ver, mas não veem. Diariamente, os limites da humanidade e da civilização são rompidos, mas parece que não queremos enxergar. Será que todos nós estamos

ficando cegos? José Saramago (1995, p. 310)

A fotografia é um fragmento representativo, um recorte do que designamos como real. O aparelho fotográfico não é mais do que um acessório técnico com o qual tentamos exprimir nossa situação existencial. "A fotografia, em sua essência, faz do fotógrafo um observador, escrivão e não poeta; esse 'ver' auxiliado pelas câmeras pode ser melhor denominado como 'visão fotográfica"' (SONTAC, 2004, p. 170).

Pensando nisto, a construção de uma imagem através do aparelho fotográfico está diretamen- 
te relacionada ao que aquele momento proporciona, não exatamente e exclusivamente à visão. Segundo Evgen Bavcar (1994) em "A luz e o cego", o olhar físico que quer ver não é o olhar da verdade, pois a veracidade de uma presença só pode ser confirmada através do toque físico. Somente o tato é o mais seguro sinal de uma existência real. Pode-se dizer que todos os outros sentidos (tato, olfato, paladar, audição), e não somente a visão, são importantes para compor um repertório imagético. É o abraço de alguém que faz lembrar de algo que passou, um perfume, uma comida, uma música...

Busco uma imagem ampla para trazer o máximo de informações possíveis, busco a essência, um ponto focal. Por exemplo: fotografar uma borboleta e poder descrever aquela imagem. Quantas informações, sobre cores, texturas, composição...Sou muito intensa em emoção, e eu uso a fotografia para criar esse diálogo. Hoje posso dizer que a fotografia me tornou outra pessoa (DOMINGUES, 2010).

A cegueira não anula a percepção representativa, ou a dimensão do todo, mas se recria no que existe de repertório imagético por meio de experiências vivenciadas. A foto produzida não é um retrato fidedigno do real, ou do que se deseja reproduzir, e sim uma expressão verdadeira da realidade invisível do imaginário.

"Hoje eu penso que daqui a 10 anos vou pegar uma foto e vou lembrar porque que a fiz, que emoção senti...aquela foto tem um momento que marcou a minha vida, e por isso me motivou a criar um fragmento daquele momento eterniżado, não é um fragmento perdido". (OTON, 2010).

O projeto desenvolvido teve como base o mestrado sobre Alfabetização Visual, realizado pelo professor João Kulcsár na Inglaterra entre 1996 e 1997, e a pesquisa como professor visitante na Universidade de Harvard, no Project Zero entre 2002 e 2003, com Howard Gardner.

Alfabetização visual é a habilidade de as pessoas realizarem um sistema de representação visual, associado com a capacidade de expressar-se por meio dele (KULCSÁR, 1997).

A premissa base sobre a Alfabetização Visual (AV) utilizada é que todo mundo tem um grau de AV. Então, uma pessoa pode ler criticamente uma imagem e pode produzir alguma imagem, seja fotografia, desenho ou pintura, enfim, ela já tem um grau de AV e a partir daí pode desenvolver mais essa competência.

Leitura e escrita são trabalhadas como prática social e, do mesmo modo que Paulo Freire, pensa-se a expressão alfabetização como o 'ler a palavra e o mundo', que supõe muito além do decodificar e codificar o impresso. E que "através do esforço das pessoas por atuar sobre o mundo, 
e por analisar e compreender os resultados de sua ação, elas chegam a conhecer melhor o mundo, de maneira mais profunda e crítica". (HERNÁNDEZ, 2009, p. 234).

Ensinar não é transferir conhecimentos, conteúdos, nem formar; é ação pela qual o sujeito criador, dá forma, estilo ou alma a um corpo indeciso e acomodado. Não há docência sem discência, as duas se explicam e seus sujeitos, apesar das diferenças que os conotam, não se reduzem a condição de objeto um ao outro...Quem ensina aprende ao ensinar, equem aprende ensina ao aprender (FREIRE, 1996, p. 154-158).

Outra base da AV éa Fotografia Participativa. Apesar de a fotografia ser naturalmente uma atividade colaborativa, este termo tem como objetivo se munir da atividade fotográfica como instrumento de comunicação visual para promover, fomentar e propagar ideias de abordagem ética, social e ideológica. É uma forma de "voz ativa" na sociedade ao seu redor, entre familiares, amigos, comunidade e outros. Encontramos no projeto um espaço para suscitar novas iniciativas que beneficiem os próprios alunos. Como, por exemplo, a mostra feita por eles com fotos sobre acessibilidade, um misto entre denúncia e reconhecimento sobre espaços acessíveis e inacessíveis na cidade de São Paulo.

Como proposto por Freire em Pedagogia da Autonomia (1996), o Projeto de Alfabetização Visual aplica a premissa de que não se ensina transferindo conhecimento, mas criando possibilidades para uma própria produção e construção dos conceitos abordados. O papel do professor/educador é fundamental na fase de fomentação e difusão das ideias; seu papel é agir como mediador entre a necessidade do aluno e melhor apresentação do recurso/método de ensino. Cada participante é único e tem suas necessidades pessoais, suas limitações quanto à parte teórica e prática.

No curso é fundamental o diálogo entre educador e aluno. Essa relação, estabelecida durante as aulas, é indispensável para criar um elo de confiança e segurança entre ambas as partes. É necessário que haja um estímulo do "olhar" por meio da descrição do espaço ao receptor, Ele precisa ser instigado para melhor representação do ambiente e uso de suas percepções com os outros sentidos, pois tudo fala; o cheiro fala, o lugar fala, o silêncio fala...

"A fotografia me permite voltar a ver o mundo de uma forma mais sensível. Eu posso enxergar o mundo com os meus olhos, mesmo não tendo a visão" (OTON, 2010).

O entrosamento, a união e unidade entre o grupo é fundamental. Dessa maneira, alunos mais experientes ajudam os que estão chegando e se tornam novos educadores. É um ciclo.

"Essa relação de ensinar e aprender de forma participativa permite ver o crescimento e amadureci- 
mento dos meus amigos. Assim como eu, eles estão conhecendo coisas novas e reconhecendo suas limitações. Juntos trocamos experiências boas e ruins, entendemos a necessidade do outro e nos ajudamos mutuamente" (ARAUJO, 2010).

\section{Vocabulário fotográfico}

Como a gente não tem a orientação visual, a gente tem que expressar um olhar de dentro. A fotografia é antes de tudo imaginar a imagem na cabeça, e depois fazer o click.

João Maia (2010).

O vocabulário fotográfico foi desenvolvido pelos educadores e professores a partir de termos conhecidos na área da fotografia. Desta forma, introduzir os alunos desde o início das aulas a este conjunto de nomenclaturas facilitou a produção das imagens.

Por mais que muitos desses conceitos pareçam abstratos no primeiro momento, cada aluno, acompanhado por seu educador nas aulas práticas, consegue, no seu próprio ritmo, se familiarizar e assimilar termos como, por exemplo, primeiro plano, plano de fundo, foco, desfoque, claro, escuro, enquadramento, entre outros.

\section{Mobilidade}

"Se a gente não fala que chegamos ao entrar na sala, para eles é como se não existíssemos..." Cláudia El Bayeh, (2008).

Este era um dos questionamentos do grupo no início do projeto - como lidar com uma pessoa com deficiência visual? Como comunicar-se com um deficiente visual? Isso foi se desmistificando com a convivência, e no decorrer das aulas foi inevitável admitir que se se relaciona com um deficiente de forma natural, apesar de certas limitações.

Visitas a ONGs e Associações foram fundamentais para o entendimento das questões da mo- 
bilidade junto a esse público, além das visitas guiadas por deficientes visuais em projetos direcionados ao público cego, como as realizadas pela Associação Brasileira de Assistência à Pessoa com Deficiência Visual (LARAMARA); a ADEVA -Associação dos Deficientes Visuais e Amigos (ADEVA); a Fundação Dorina Nowill para Cegos, entre outros. Esses encontros foram' definitivos para entender melhor o universo deste público.

"As pessoas videntes, às vezes, não percebem o mundo ao seu redor. As pessoas têm medo da proximidade com o deficiente, de não saber como lidar". (MORAES, 2010).

\section{Como produzir imagens?}

Esta é uma curiosidade comum entre todos, até mesmo entre os alunos que se interessam pelo curso. "Fiquei com muita curiosidade...até fiquei sem dormir essa semana querendo saber como é que vamos conseguir fotografar. Vamos conseguir o foco? Como é que vamos saber o que é que estamos fazendo?", disse Sivanildo Lima, (2008) em seu primeiro dia de aula.

A construção e produção da imagem são feitas em conjunto. Em sala de aula o imaginário é estimulado por meio de dinâmicas de "quebra-gelo", sensibilização e descrição das imagens. Com apoio de materiais pedagógicos inserimos o aluno ao mundo das referências. Esses materiais são táteis, em alto relevo, e ajudam a compor o repertório imagético e a descrição da foto.

Mas como eles produzem as imagens? Será descrita aqui uma das possiblidades que se apresenta nesse processo.

Após a aula teórica, os alunos recebem uma tarefa a ser cumprida. Cada aluno sai acompanhado de um educador, que o ajuda na locomoção e descrição do ambiente. A partir disso, o aluno forma uma idealização daquilo que deseja retratar, comenta com o educador que o auxilia na realização da imagem.

Como na foto abaixo, em que a educadora Márcia Lima está auxiliando Bê Morais a tirar uma foto de uma escultura. Depois do click, o educador observa a imagem e a descreve para o aluno. Caso não tenha saído como ele imaginou, sem foco, cortada, enfim, a foto é refeita até que o fotógrafo se sinta satisfeito com o resultado e a fotografia transmita seu objetivo.

Sempre existirão detalhes que escaparão, como comentou Bavcar sobre a produção de suas imagens: "Eu sei que há sempre coisas que me escapam, mas também acontece com os fo- 
tógrafos que podem ver fisicamente" (BAVCAR 2010). Com o tempo e a prática, cada aluno vai conhecendo melhor o seu corpo, encontrando assim um ponto de equilíbrio para colocar a câmera e referências quanto à distância até o assunto fotografado.

Por exemplo, quando a proposta é tirar o retrato de alguém, é utilizado o toque nos ombros para reconhecer a altura do fotografado. Pede-se também que a pessoa que será retratada converse com o fotógrafo, porque é através do som da voz é que poderá ser reconhecida a distância entre um e outro.

Essas são práticas aprendidas em aula, em parceria e com auxílio participativo entre alunos, coordenadores e educadores.

\section{Imagem 3-Aula prática.}

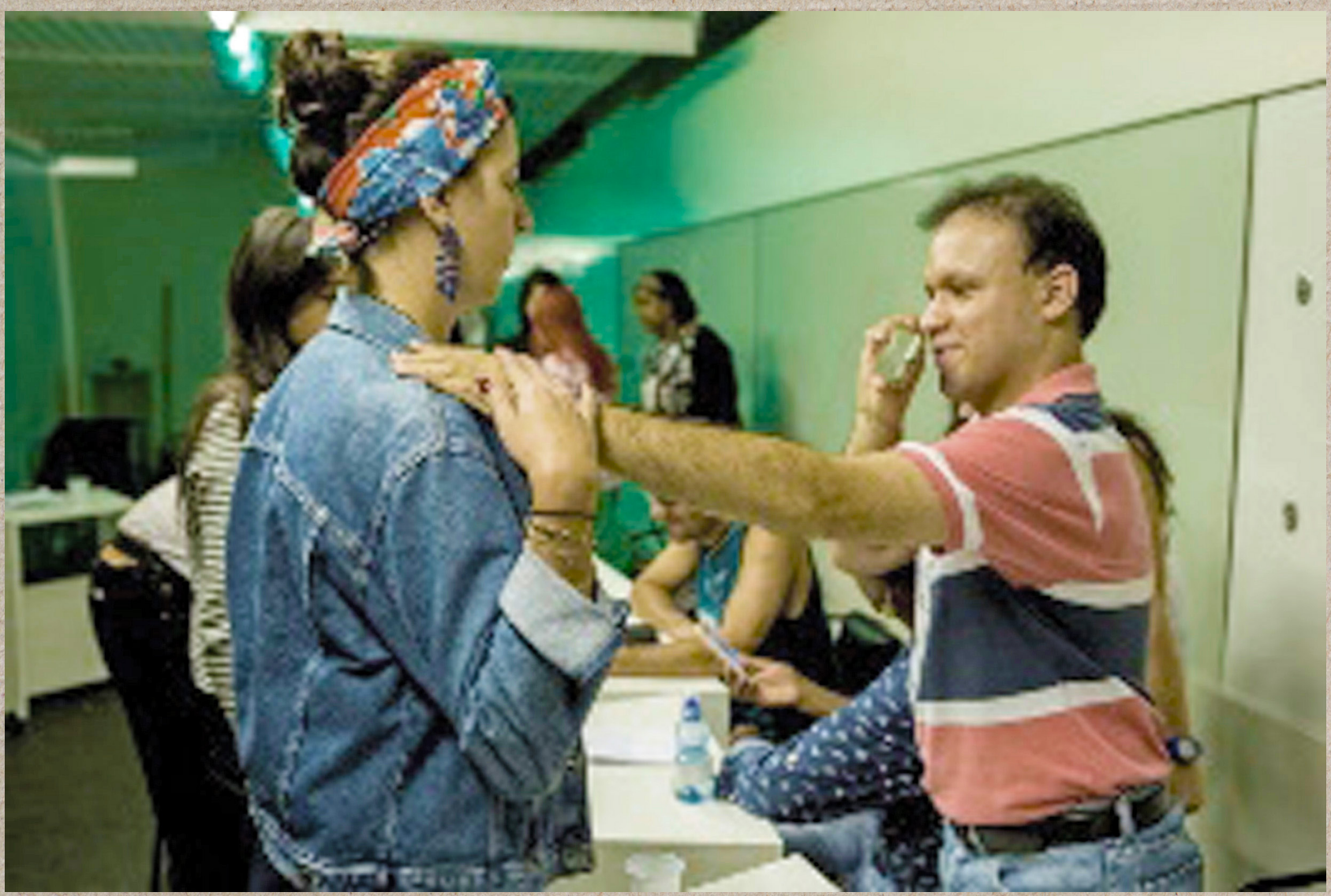

Fonte: Acervo pessoal de Gabriel Cardoso (2015).

Descrição da imagem: Foto na horizontal, colorida. A imagem tem um homem e uma mulher em primeiro plano e da cintura para cima. No plano de fundo há outras pessoas. Ele coloca a câmera próximo ao próprio rosto com a mão direita e a mão esquerda coloca no ombro dela. Ela coloca a mão sobre a mão dele. Ele está de jeans e camisa listrada horizontal. Ela está com jaqueta jeans, lenço no cabelo e brincogrande. 


\section{Como descrever as imagens produzidas?}

Estamos muito imersos numa cultura de imagens prontas, um dinamismo de complexidades e informações visuais. O que se afirma é que a visão é o mais importante dos recursos da percepção. Sob essa perspectiva, podemos perder as oportunidades de vivenciar experiências estéticas que são proporcionadas pela sensibilização dos outros sentidos, criando e recriando outras alternativas de olhar.

Em sala de aula, para descrever as imagens produzidas de forma que se alcance um entendimento e se instigue o imaginário do aluno, são utilizados três métodos, que serão descritos mais detalhadamente abaixo: imagem em alto relevo, descrição e audiodescrição.

$O$ ato de descrever uma imagem para o outro é e sempre será um ato incompleto, porque a incompletude está presente em tudo que é visto pelos olhos humanos. Não cabe ao descritor interferir no sentido, no significado e na mensagem que o artista/fotógrafo quis passar, criando assim uma ressignificação. O seu papel é traduzir as imagens de uma forma que propicie à pessoa com deficiência visual a oportunidade de fazer sua própria interpretação.

\section{Alto relevo}

Este recurso é usado como parte do material pedagógico (um conjunto de imagens de vários fotógrafos em alto relevo, com diferentes texturas) entregue aos alunos. Quando se aborda novas referências na fotografia, é feita uma aplicação de cola alto-relevo ou materiais que tenham textura, como papel veludo, pedaços de madeira, algodão, caroço de arroz etc., para que, ao se falar sobre determinada imagem, o aluno consiga ter uma relação mais "palpável" por meio do tato.

O professor/educador descreve a imagem e o aluno pode senti-la ao passar os dedos sobre o papel. Como nas imagens abaixo:

Na primeira foto, um exemplo de aplicação de cola; já na segunda, aplicações com diferentes texturas. 
Imagem 4-Álbum de Fotografia tátil.

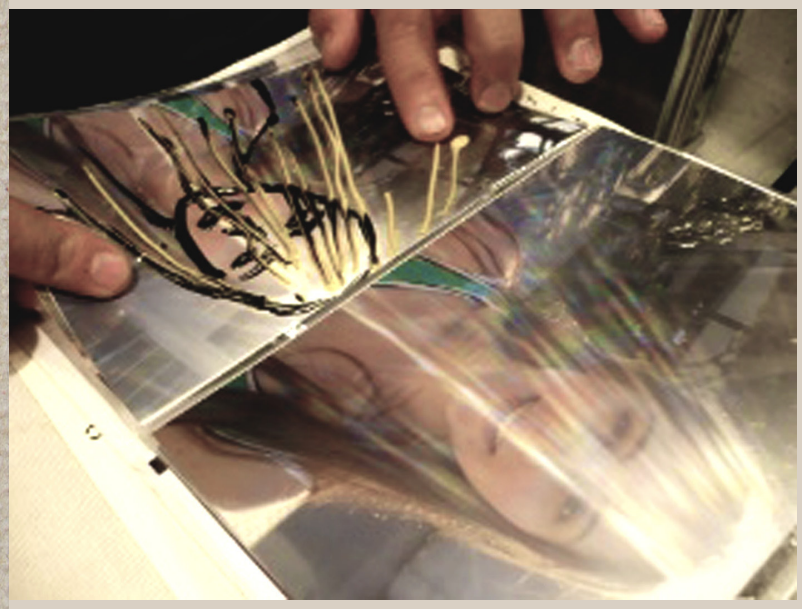

Descrição da imagem: Foto na horizontal, colorida. A imagem mostra, na parte superior, os dedos de uma pessoa passando sobre um álbum de fotos. Esta foto tem cola alto-relevo. No lado direito da imagem temos a fotografia original, o retrato de uma menina, dos ombros para cima ocupando todo quadro. Raios de sol sobre sua cabeça invadem a foto e cobrem seu rosto como um véu delicado.

Fonte: Acervo pessoal de Fernanda Souza (2008)

Imagem 5-Imagem tátil

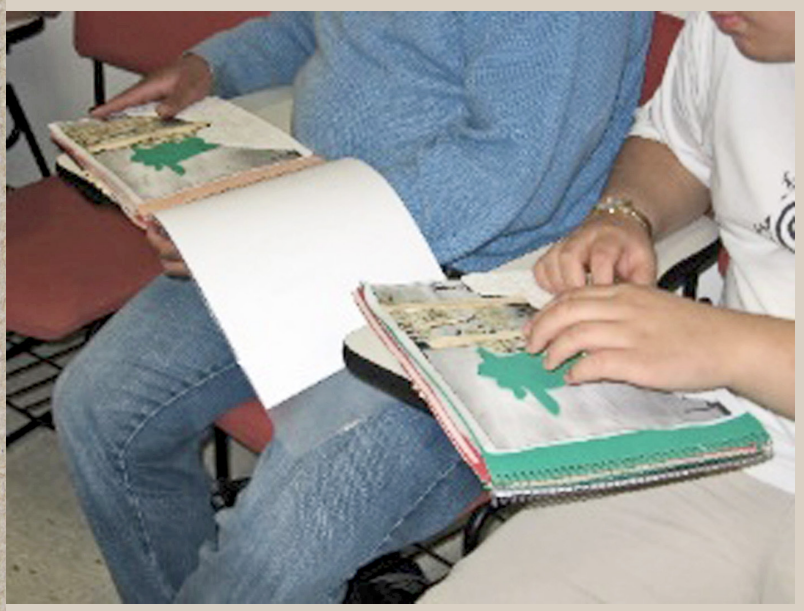

Descrição da imagem. Foto mostra duas pessoas sentadas em cadeiras universitárias, mas sem mostrar o rosto delas, só as pernas e as mãos passando sobre uma foto em relevo.

Fonte: Acervo pessoal de Carolina Moraes (2008)

\section{Como descrevemos as imagens?}

Durante o curso fez-se necessária a adaptação e criação de novas abordagens para descrever as imagens. Os alunos não devem produzir sem saber o que e como está sendo feito. Faz parte do processo de ensino participativo a construção dos resultados de modo coletivo.

As descrições produzidas são livres, mas em ação conjunta em sala de aula são delineadas questões norteadoras para auxiliar na produção individual/pessoal de cada descritor. Assim, qualquer pessoa que esteja presente em seu cotidiano poderá fazê-lo. 


\section{Processo de descrição das imagens produzidas}

Foi necessário reconhecer elementos primordiais para a descrição das imagens, tais como:

Elementos denotativos e, em sequência, os conotativos.

. Formato: horizontal, vertical, panorâmico...

- Colorida ou preto e branco

- Qual é área da fotografia: retrato, paisagem, still (objeto), arquitetura

- Principais objetos da cena e a sua proporção

- Posição do fotógrafo: abaixo do objeto principal, na altura do objeto ou acima do óbjeto

- Plano: aberto, fechado, close-up, americano, meio corpo, $3 / 4$

- Primeiro plano e plano de fundo

- Cores predominantes

- Elementos que complementem de forma sucinta a compreensão

- Se for um retrato, informar qual é a expressão do personagem

- Palavras que expressem o sentimento da foto

Cada foto é uma foto, sendo assim, muitas vezes não é necessário o uso de todos os elementos propostos acima. Esta lista de perguntas se propõe a auxiliar na produção da descrição, como um ponto de partida, já que não existe uma referência na produção oficial da audiodescrição para fotografia.

\section{Produtos do projeto}

Desde o início da primeira turma os alunos desejaram mostrar os resultados por meio de exposições e catálogos. A razão principal sempre foi dizer que as pessoas deficientes visuais podem 
fazer tudo que os videntes podem e também mostrar para a família que eles são capazes, pois muitas vezes é na família que eles encontram mais preconceito por serem deficientes visuais.

Entre os produtos do projeto temos as exposições fotográficas acessíveis, como por exemplo: Acessibilidade, fotografias feitas por pessoas deficientes visuais, em 2009 no Centro Universitário Senac-SP.

Imagem 6-Catálogo da exposição Acessibilidade.

A C E S S I B I L I D A DE

$\cdot \cdot \because \because \because \because \because \cdots \because \cdot \bullet$

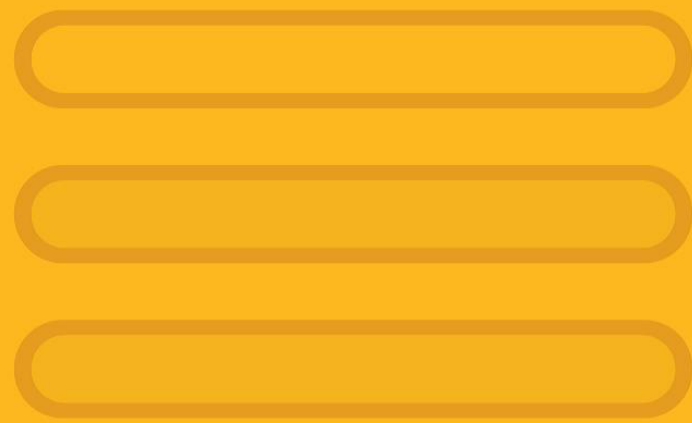

FOTOGRAFIAS FEITAS POR DEFICIENTES VISUAIS
Descrição da imagem: Capa de catálogo, quadrada com cor laranja, a mesma que o piso tátil. No centro, as mesmas faixas do piso tátil. Na parte superior, a palavra Acessibilidade, em cor preta, e abaixo a mesma palavra em braille. $\mathrm{Na}$ parte inferior, uma frase em cor preta: Fotografias feitas por deficientes visuais.

Fonte: Acervo pessoal de João Kulcsár, Catálogo da exposição (2009).

Outro exemplo mais recente, temos a mostra realizada em novembro de 2015 na Pinacoteca do Estado de São Paulo, com fotos ampliadas em tamanho $50 \times 75 \mathrm{~cm}$, resultado de um curso de nove aulas entre setembro a outubro.

Exposição fotográfica TRANSVER - fotografias feitas porpessoas deficientes visuais, inspirada pelo poema de Manuel de Barros:

"O olho vê, a lembrança revê, e a imaginação transvê.

É preciso transver o mundo." (BARROS, 2001).

Os dez participantes foram sensibilizados pelas poesias de Manuel de Barros, pelos trabalhos de importantes fotógrafos contemporâneos e pelo material multissensorial do acervo da Pinacoteca e criaram novos significados e perspectivas a respeito do espaço cultural a partir de percepções, exceto a visão para "transverem" o mundo, tornando o invisível em visível. 


\section{Exposição acessível na Pinacoteca}

\section{Imagem 7-Panorâmica da exposição}

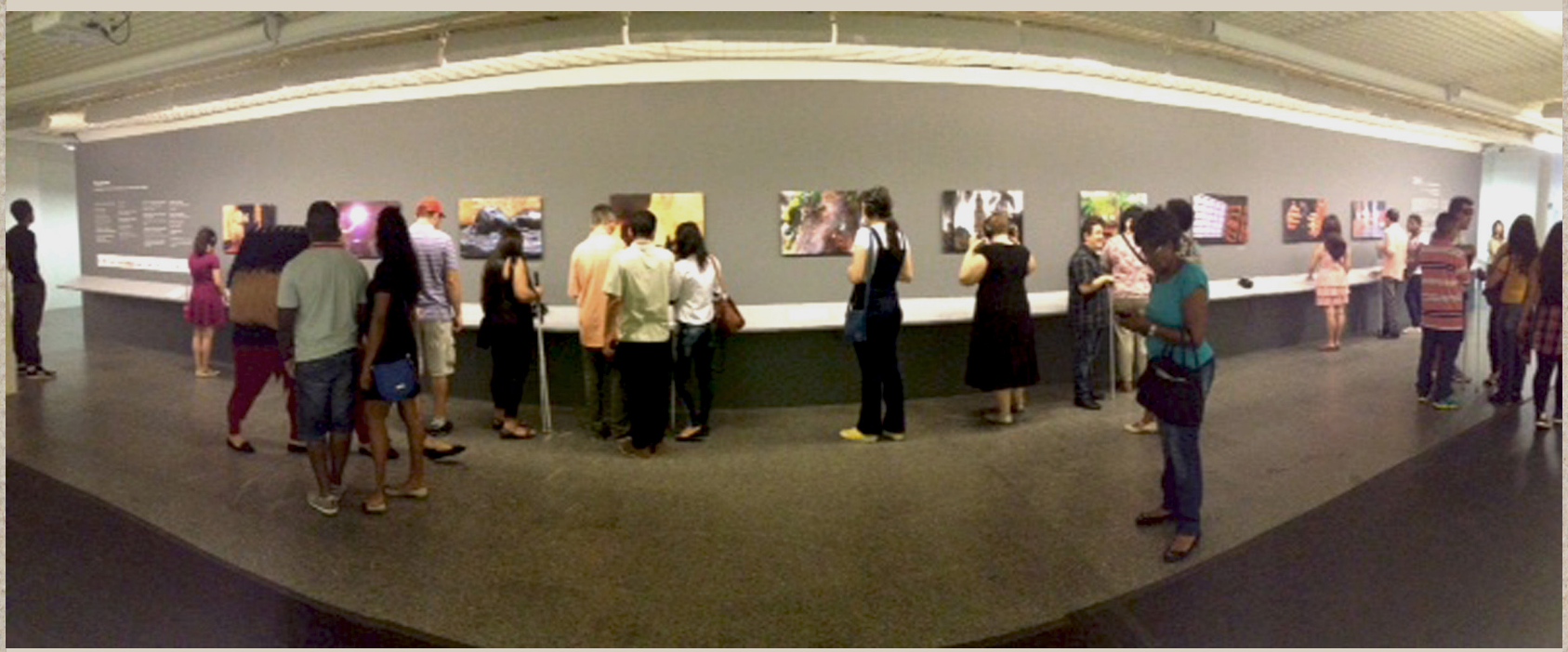

Fonte: Acervo Pessoal de Gabriel Cardoso (2015).

Descrição da imagem. Foto panorâmica da exposição fotográfica, com cerca de 20 pessoas vendo e tocando os relevos. A parede e o piso são cinza.

Imagem 8- Foto da exposição.

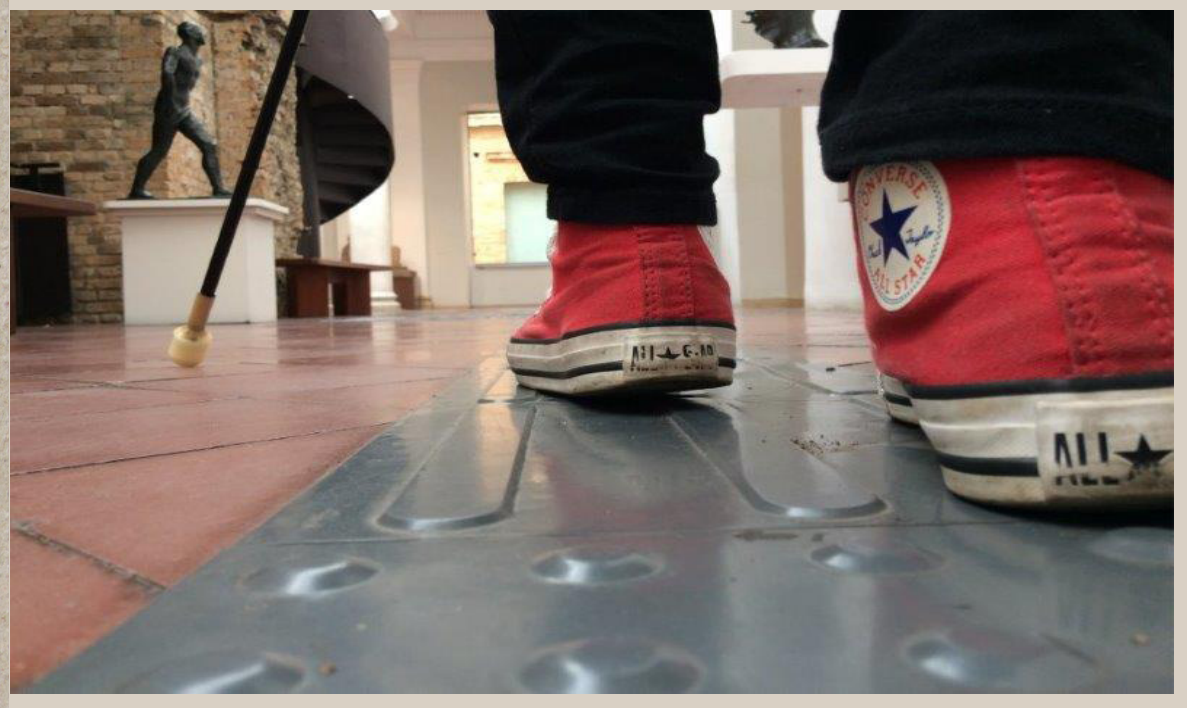

Fonte: Acervo pessoal de Bia Santana (2015).
Descrição da imagem.

Foto colorida e horizontal.

A câmera está posicionada sobre o chão. Em primeiro plano o tênis all star vermelho de Bia, que anda sobre o piso tátil cinza. A calça dela é preta, mas só vemos a té o seu tornozelo. A perna esquerda está à frente da esquerda, dando a sensação de estar andan-
te. No plano de fundo, uma do. Do lado esquerdo, Bia tem uma bengala guia, que aparece só em parte. No plano de fundo, uma estátua de bronze de um homem num pedestal, uma parede de tijolos e outras pintadas de branco da Pinacoteca. 
Os modos de ver que se

apresentam para pessoas deficientes visuais se completam pelas palavras e pelos outros sentidos. Ao dispararem o botão da câmera, focando a acessibilidade, pessoas com deficiência visual propõem uma discussão sobre a questão da técnica e da estética fotográfica, além de transformaro ato de fotografar num ato político, que nos faz repensar o conceito de cegueira. Afinal, será que não estamos todos cegos?

"O que vemos, não é o que vemos, senão o que somos."

Fernando Pessoa (2011, p 55-56).

Certo provérbio diz que uma imagem vale mil palavras, mas prefiro dizer que uma imagem vale mil perguntas. Pessoas deficientes visuais ao realizarem 0 ato de fotografar provocam as mil perguntas. As mais recorrentes são: Como os deficientes visuais fotografam? Talvez a melhor questão seria... por que eles querem fotografar? Eles dizem que é pelas mesmas razões que todos fotografam: para guardar o momento, se expressar, compartilhar com os outros e, por fim, suprir uma necessidade básica do ser humano de produzir e consumir imagens para se sentir participantes desta sociedade de hipervisibilidade. A segunda questão recorrente é porque pessóas cegam fotografam se não veem nada? Sabemos que não existe uma forma única de registrar o mundo e que o cérebro humano tem mais de trinta áreas conectadas para a visualização, desta maneira mesmo sem a alimentação do aparelho ocular uma pessoa cega continua criando imagens mentais e visões interiores, operando no espaço entre as limitações fisiológicas do ver e o desejo de fazer imagens.

Os modos de ver que se apresentam para pessoas deficientes visuais se completam pelas palavras e pelos outros sentidos. Ao dispararem o botão da câmera, focando a acessibilidade, pessoas com deficiência visual propõem uma discussão sobre a questão da técnica ẹ da estética fotógráfica, além de transformar o ato de fotografar num ato político, que nos faz repensar o conceito de cegueira. Afinal, será que não estamos todos cegos?

\section{Referências}

ARAUJO, Lelo. Entrevista concedida a João Kulcsár, São Paulo, 6 de abril de 2010. AOKI, Henrique. Entrevista concedida a João Kulcsár, São Paulo, 6 de abril de 2010. 
BARREIRA, Clodoaldo. Entrevista concedida a João Kulcsár, São Paulo, 6 de abril de 2010.

DOMINCUES, Cláudia. Entrevista concedida a João Kulcsár, São Paulo, 6 de abril de 2010.

EL BAYEH, Cláudia. Entrevista concedida a, João Kulcsár, São Paulo, 10 de setembro de 2008.

LIMA, Sivanildo. A. Entrevista concedida a João Kulcsár, São Paulo, 6 de abril de 2010.

MAIA, João. Entrevista concedida a João Kulcsár, São Paulo, 6 de abril de 2010.

MORAES, Bê. Entrevista concedida a João Kulcsár, São Paulo, 6 de abril de 2010.

OTON, Marco. Entrevista concedida a João Kulcsár, São Paulo, 6 de abril de 2010.

SILVEIRA, Gabriel. Entrevista concedida a João Kulcsár, São Paulo, 6 de abril de 2010.

SILVA, Marina. Entrevista concedida a João Kulcsár, São Paulo, 6 de abril de 2010.

BARROS, Manoel de. Livro sobre nada. 9. ed. Rio de Janeiro: Record, 2001.

BAVCAR, Evgen. A luz e o cego. In: NOVAES, A. (Org.). Artepensamento. São Paulo: Companhia das Letras, 1994. p. 461-466.

. Estética do (In)visível. 2010. (9m32s) Disponível em: https://www.youtube.com/ watch? $v=U 0 G Y$ e7l-tgw. Acesso em: 09 mar.2018.

FREIRE, Paulo. Pedagogia da Autonomia - Saberes necessários à prática educativa, 1996. cap 1.

HERNÁNDEZ, Fernando. Cultura visual, mudança educativa e projeto de trabalho. Porto Alegre: Artmed, 2009.

JANELA da Alma. Direção: João Jardim e Walter Carvalho. Produção: Tambelini Filmes e Produções Audiovisuais. 20011.1 DVD (64min). 2002.

KULCSÁR, João. Alfabetização visual. 2017. Disponível em:<http://www.alfabetizacaovisual.com.br/deficientes_visuais/>. Acesso em: 18 out. 2017.

Visual literacy and the role of practical photography in teaching with reference to specific projects in Brazilian and English communities. Dissertação (Mestrado em Artes) - Universidade de Kent, Canterbury. 1997.

MERLEAU-PONTY, Maurice. O olhoe o espírito. São Paulo: Cosac \& Naify, 2004.

PESSOA, Fernando. Livro do desassossego. Companhia das Letras: São Paulo, 2011.

SARAMACO, José. Ensaio sobre a cegueira. São Paulo: Companhia das Letras, 1995.

SONTAC, Susan. Sobre fotografia. Tradução Rubens Figueiredo. São Paulo: Companhia das Letras, 2004. 